\title{
Effect of Phyllanthus emblica L. fruit on improving regulation of methylglyoxal-induced insulin resistance in 3T3-L1 cells
}

\author{
Hui-Chi Chen ${ }^{\mathrm{a}, \dagger}$, Yu-Tang Tung, ${ }^{\mathrm{b}, \dagger}$, Sheng-Yi Chen ${ }^{\mathrm{a}}$, Jer-An Lin ${ }^{\mathrm{c}}$ and Gow-Chin Yen ${ }^{\mathrm{a}, \mathrm{c}^{*}}$
}

\begin{abstract}
aDepartment of Food Science and Biotechnology, National Chung Hsing University, 145 Xingda Road, Taichung 40227, Taiwan
${ }^{\mathrm{b}}$ Graduate Institute of Metabolism and Obesity Sciences, Taipei Medical University, $250 \mathrm{Wu}$-Hsing Street, Taipei 110, Taiwan

${ }^{\mathrm{c}}$ Graduate Institute of Food Safety, National Chung Hsing University, 145 Xingda Road, Taichung 40227, Taiwan

$\dagger$ These authors contributed equally to this work.

*Corresponding author: Gow-Chin Yen, Department of Food Science and Biotechnology, National Chung Hsing University, 145 Xingda Road, Taichung 40227, Taiwan. Tel: +886-4-2287-9755; Fax: +886-4-2285-4378; E-mail: gcyen@nchu.edu.tw
\end{abstract}

DOI: $10.31665 / \mathrm{JFB} .2018 .4170$

Received: December 04, 2018; Revised received \& accepted: December 21, 2018

Citation: Chen, H.-C., Tung, Y.-T., Chen, S.-Y., Lin, J.-A., and Yen, G.-C. (2018). Effect of Phyllanthus emblica L. fruit on improving regulation of methylglyoxal-induced insulin resistance in 3T3-L1 cells. J. Food Bioact. 4: 139-149.

\begin{abstract}
The increasing methylglyoxal (MG) level of body has been found in people with obesity and insulin resistance, resulting from their dietary style and abnormal metabolic functions. MG promotes inflammation, oxidative stress, glycation, and all of which are closely related to insulin resistance and chronic diseases. Phyllanthus emblica $\mathrm{L}$. fruit has various bioactivities such as anti-inflammation, anti-diabetes, anti-nonalcoholic fatty liver, and anti-dyslipidemia. Therefore, this study was aimed to investigate the effects of water extract of $P$. emblica (WEPE) and its enriched compound, ellagic acid, on MG-induced inflammation, insulin resistance, and lipogenesis in 3T3-L1 cells. The results showed that MG activated the peroxisome proliferator activated receptor-gamma (PPAR $\gamma$ ) and CCAAT/ enhancer-binding protein alpha (C/EBP $\alpha)$, which can increase adipogenesis in adipocytes. In addition, MG enhanced pro-inflammatory cytokine IL-6 protein expression and release through the activation of MAPK and NF-KB signaling pathway, as well as increasing the monocyte chemoattractant protein-1 expression to cause macrophage infiltration. MG also significantly reduced glucose uptake, indicating that insulin resistance in obese patients may be related to MG generation. WEPE and ellagic acid effectively decreased IL-6 protein expression and cytokine release through inactivation of JNK and p65 pathways. WEPE and ellagic acid significantly increased glucose uptake and reduced insulin resistance by MG treatment. WEPE also decreased the protein-tyrosine phosphatase $1 B$ to reduce insulin resistance and inhibited MG-induced fat accumulation related proteins such as PPAR $\gamma, C / E B P \alpha$, FAS, and p-ACC. Therefore, WEPE may have the potential to ameliorate MG-induced inflammation, increase glucose uptake, and decrease fat accumulation.
\end{abstract}

Keywords: Methylglyoxal; 3T3-L1 cells; Insulin resistance; Inflammation; Phyllanthus emblica.

\section{Introduction}

More than 1.5 billion people around the world are overweight, among which about 5 million are obese (Hammond and Levine, 2010). Obesity not only consumes much of the healthcare resources but also increases the probability of insulin resistance, type 2 dia- betes, abnormal lipid metabolism, cardiovascular disease, and cancers (Han and Lean, 2016). Additionally, over nutrition and obesity activates the immune system resulting in inflammation, which has a significant relationship with chronic diseases (Gerriets and MacIver, 2014). The main cause of obesity is excessive energy intake and too much energy being stored in the adipose tissue, which is 
composed of pre-adipocytes and adipocytes. The hypertrophy adipocytes enhance pro-inflammatory cytokines, monocyte chemoattractant protein-1 (MCP-1), and free fatty acids that can promote macrophage infiltration to adipose tissue (Kamei et al., 2006). Inflammatory cytokines cause abnormal phosphorylation of IRS1 resulting in excessive insulin secretion by the pancreas, which finally leads to insulin resistance. Excessive insulin cannot be utilized by the cells, which inhibit glucose uptake in adipose tissue and increase inflammatory cytokines (Qatanani and Lazar, 2007).

Previous studies have shown that the plasma concentrations of advanced glycation end products (AGEs) and methylglyoxal (MG) are increased in obesity and in patients with insulin resistance (Bo et al., 2016). Furthermore, long-term intake of AGEs and MG could increase AGEs and MG levels in the body, and circulating of AGEs in the body is not easily eliminated (Sims et al., 2010; Tikellis et al., 2014). In addition, AGEs and MG generate oxidative stress and promote the chronic inflammation, which are an important factor in insulin resistance (Kellow et al., 2014; Dong et al., 2016).

Phyllanthus emblica L. fruit is mainly grown in tropical and subtropical regions, and enriches in a variety of biologically active compounds such as flavonoids, polyphenols and vitamin C. Previous studies have shown that the extract of $P$. emblica fruit can improve blood pressure, fatty liver, nonalcoholic steatohepatitis, diabetes, inflammation, antioxidant, and cancer (Fugh-Berman, 2000; Nain et al., 2012; Muthuraman et al., 2011; Ansari et al., 2014; Zhao et al., 2015; Tung et al., 2018). However, the effect of $P$. emblica fruit on methylglyoxal-induced insulin resistance remains unclear. Therefore, the objective of this study was to investigate the effect of $P$. emblica fruit extract on MG-induced inflammation, lipid metabolism, and insulin resistance in 3T3-L1 cells.

\section{Material and methods}

\subsection{Materials}

Glycine, methylglyoxal, isopropanol, gallic acid, ellagic acid, Oil Red $\mathrm{O}, N, N, N^{\prime}, N^{\prime}$,-tetramethylethylenediamine (TEMED), TWEEN 20, bovine serum albumin (BSA), anti- $\beta$-actin antibody, and sodium dodecyl sulfate (SDS) were purchased from Sigma-Aldrich company (St. Louis, MO, USA). Anti-IL-6 antibody and antiprotein-tyrosine phosphatase 1B (PTP1B) antibody were purchased from Abcam (Cambridge, UK). Nitrocellulose (NC) membrane, anti-peroxisome proliferator activated receptor-gamma (PPAR $\gamma$ ) antibody, and dimethyl sufoxide (DMSO) were purchased from Merck Millipore (Darmstadt, Germany). Mouse IL-6 ELISA Ready-SETGO kit was purchased from eBioscience Company (San Diego, CA, USA). Anti-JNK antibody, anti-phospho-JNK antibody, anti-p65 antibody, anti-phospho-p65 antibody, and anti-CCAAT/enhancerbinding protein alpha $(\mathrm{C} / \mathrm{EBP} \alpha)$ antibody were purchased from Santa Cruz Biotechnology, Inc. (Dallas, TX, USA). Glucose uptake Cell-Based assay kit was purchased from Cayman Chemicals Company (Ann Arbor, MI, USA). Penicillin-streptomycin solution (PS) and DMEM (High glucose) were purchased from the Thermo Fisher Scientific (Waltham, MA, USA). Anti-phospho-acetyl-CoA carboxylase (ACC) antibody and anti-ACC antibody were purchased from Cell Signaling Technology Corporation (Danvers, MA, USA). Anti-fatty acid synthase (FAS) antibody was purchased from Gene Tex Corporation (Irvine, CA, USA).

\subsection{Cell differentiation}

Mouse preadipocytes lines, 3T3-L1 (purchased from BCRC No.
60159), was cultured in Dulbecco's modified Eagle's medium (DMEM) containing 10\% fetal bovine serum (FBS), $4.5 \mathrm{~g} / \mathrm{L}$ glucose, $4 \mathrm{mM}$ L-glutamine, $1.5 \mathrm{~g} / \mathrm{L}$ sodium bicarbonate and 1\% PS (100 units/mL pencillin and $100 \mu \mathrm{g} / \mathrm{mL}$ streptomycin). Cells were incubated in a $5 \% \mathrm{CO}_{2}$ incubator at $37{ }^{\circ} \mathrm{C}$. Cells were cultured to about $70 \%$ confluence, and then cell differentiation was induced by changing the medium to differentiation medium I (DMEM containing $0.5 \mathrm{mM}$ 3-isobutyl-1-methylxanthine, $1 \mu \mathrm{M}$ dexamethasone, $1 \mu \mathrm{M}$ insulin, $1.5 \mathrm{~g} / \mathrm{L}$ sodium bicarbonate, $10 \% \mathrm{FBS}$, and $1 \% \mathrm{PS}$ ). After $48 \mathrm{~h}$, the medium was changed to differentiation medium II (DMEM containing $1 \mu \mathrm{M}$ insulin, $1.5 \mathrm{~g} / \mathrm{L}$ sodium bicarbonate, $10 \% \mathrm{FBS}$, and $1 \% \mathrm{PS}$ ) for 4 days. The differentiation medium II was refreshed on days $8,10,12$, and 14. Intracellular lipid droplets were increased in both number and size in the cell differentiation.

\subsection{Quantification of methylglyoxal (MG)}

Quantification of MG was carried out by HPLC according to the method of Arribas-Lorenzo and Morales (2010). O-phenylenediamine (OPD) was used to derivatize MG into stable 2-methylquinoxaline (2-MQ), and then 2-MQ was analyzed by HPLC. The cell culture medium of preadipocytes or adipocytes was mixed with $0.45 \mathrm{~N}$ perchloric acid for $5 \mathrm{~min}$, and then added $10 \mathrm{mM} \mathrm{OPD}$ at $37{ }^{\circ} \mathrm{C}$ for $2 \mathrm{~h}$ following at $60^{\circ} \mathrm{C}$ for $1 \mathrm{~h}$. After derivatization with OPD, the sample was loaded onto the solid phase extraction (SPE) column and then the content of 2-MQ was determined by HPLC. A standard calibration curve of 2-MQ was constructed with a series of concentrations of standard compounds. In addition, different concentrations $(1-100 \mu \mathrm{g} / \mathrm{mL})$ of $\mathrm{MG}$ were prepared in accordance with the above-described reaction to obtain a standard calibration curve of 2-MQ in order to determine the concentration of MG. Samples were separated by chromatography with LichroCART $^{\circledR}(250 \mathrm{~mm} \times 4 \mathrm{~mm}$, Merck $)$ column. Elution was performed isocratically with a mixture of $0.5 \%(\mathrm{v} / \mathrm{v})$ acetic acid in water and methanol (40:60, v/v) with a detection (Hitachi L-2400 ELITE LaChrom) of $315 \mathrm{~nm}$, and flow rate of $0.7 \mathrm{~mL} / \mathrm{min}$.

\subsection{Extraction of WEPE}

P. emblica fruit was generously supplied by the Miaoli District Agricultural Research and Extension Station, Council of Agricultural, Executive Yuan (Miaoli, Taiwan). The dry powder of P. emblica fruit was added to double-distilled water on a rotary shaker (120 rpm) at $25^{\circ} \mathrm{C}$ overnight. The water extract of $P$. emblica fruit (WEPE) was decanted, filtered under vacuum, concentrated in a rotary evaporator, and then lyophilized. Furthermore, the extract was stored at $-20{ }^{\circ} \mathrm{C}$ for assay. The yield of the extract contains two compounds consist of gallic acid and ellagic acid.

\subsection{Oil red $O$ assay}

The 3T3-L1 adipocytes were seeded in 6-well plate, and then 0, 10, 50 , or $100 \mu \mathrm{M} \mathrm{MG}$ was added for 3 days or 6 days. At the end, the cells were washed twice with PBS and fixed in 10\% neutral buffered formalin for $20 \mathrm{~min}$. After the cells were covered with $100 \%$ propylene glycol for $3 \mathrm{~min}$, the cells were stained with $5 \mathrm{mg} / \mathrm{mL}$ oil red $\mathrm{O}$ solution for $60 \mathrm{~min}$. After the stain was removed, the cells were decolored with $60 \%$ propylene glycol and then washed with PBS. Representative photomicrographs were captured at a $200 \times$ magnification using a camera mounted onto a microscope (Olym- 
a
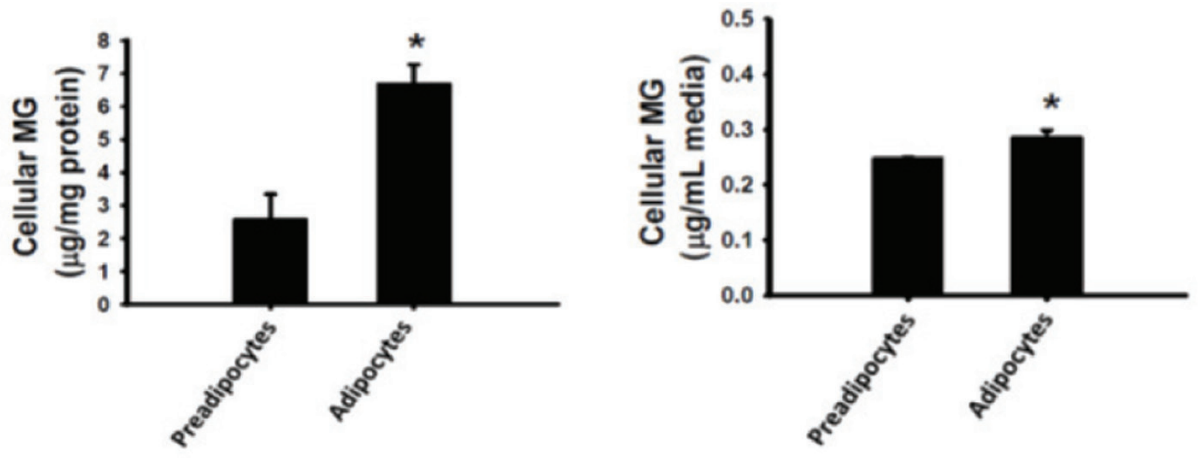

b
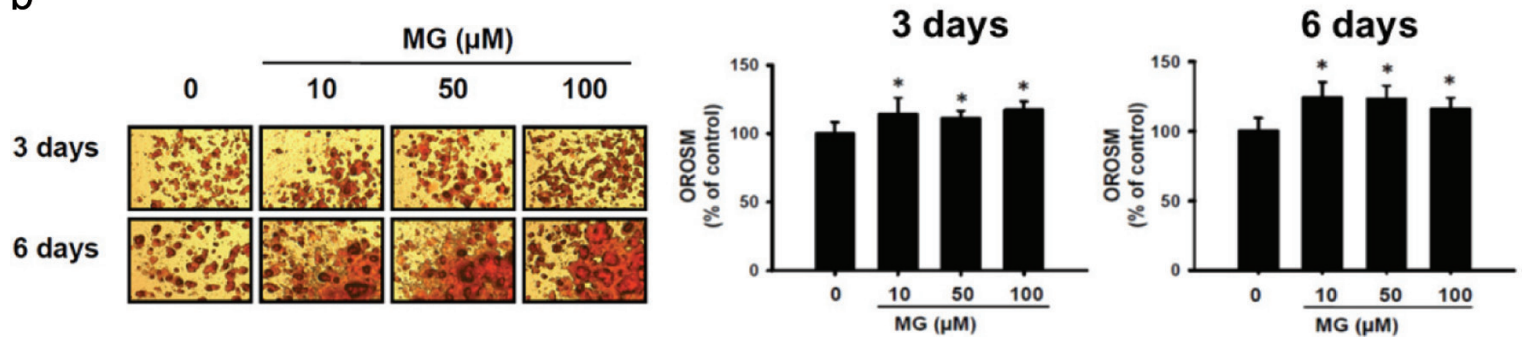

Figure 1. Oil droplets accumulation by methylglyoxal (MG) treatment. (a) Determination of both intracellular and extracellular MG as 2-methylquinoxaline by high-performance liquid chromatography (HPLC). The data were expressed as the mean \pm SD $(n=3)$. ${ }^{*} p<0.05$ compared to preadipocyte. (b) Effects of methylglyoxal (MG) on Oil red O stained material (OROSM) in 3T3-L1 adipocytes. Cells were treated with 10, 50, and 100 $\mu \mathrm{M}$ of MG for 3 days and 6 days.

pus, Osaka, Japan) and intracellular lipid droplets were analyzed using ImagePro (Media Cybernetics, Bethesda, MD, USA). Oil red O-stained material (OROSM) was extracted using isopropanol, and the absorbance was measured at a wavelength of $520 \mathrm{~nm}$ using a spectrophotometer.

\subsection{Analysis of the proteins}

The 3T3-L1 adipocytes were pretreated with $0,10,50$, or $100 \mu \mathrm{M}$ MG for $48 \mathrm{~h}$, or co-treated with $10 \mu \mathrm{M}$ MG and test samples (different concentrations of WEPE or $5 \mathrm{mM} \mathrm{AG}$ ) for $48 \mathrm{~h}$. The expressions of IL-6, p-JNK, JNK, p-p65, p65, PPAR $\gamma$, C/EBP $\alpha$, MCP-1, PTP1B, p-ACC, ACC, and FAS in cell extract proteins were analyzed using western blot analysis. The western blot analysis was carried out following the method of Cheng et al. (2014).

\subsection{Enzyme-linked immunosorbent assay}

The 3T3-L1 adipocytes were pretreated with $0,10,50$ or $100 \mu \mathrm{M}$ MG for $48 \mathrm{~h}$, or co-treated with $10 \mu \mathrm{M} \mathrm{MG}$ and test samples (different concentrations of WEPE or $5 \mathrm{mM} \mathrm{AG}$ ) for $48 \mathrm{~h}$. IL-6 was measured using a specific ELISA kit as indicated by the manufacturer's instructions.

\subsection{Glucose uptake assay}

The 3T3-L1 adipocytes were exposed to $100 \mathrm{nM}$ insulin for $1 \mathrm{~h}$ and continuously treated with $0,10,50$ or $100 \mu \mathrm{M} \mathrm{MG}$ for $48 \mathrm{~h}$, or cotreated with $10 \mu \mathrm{M}$ MG and test samples (different concentrations of WEPE or $5 \mathrm{mM} \mathrm{AG}$ ) for $48 \mathrm{~h}$. Glucose uptake assay was measured using Glucose Uptake Cell-Based Assay Kit (Cayman, Ann Arbor, MI, USA). Finally, the cells were detected using a flow cytometer
(Becton Dickson Immuno-cytometery System USA, San Jose, CA, USA) and then analyzed using Cell Quest analysis software.

\subsection{Statistical analysis}

Data were expressed as the means $\pm \mathrm{SD}$. The significance of difference was calculated by Duncan's test, and results with $p<0.05$ were considered to be statistically significant.

\section{Results}

\subsection{Effects of MG contents and Oil red $O$ stained material (OR OSM) in MG-induced insulin resistance}

There is an increased accumulation of AGEs in obesity and diabetes compared to normal subjects (Vlassara and Striker, 2011). MG was the main precursor of AGEs (Brix et al., 2012), and therefore the MG contents of 3T3-L1 preadipocytes and adipocytes were determined in this study. Figure 1a showed that the MG contents of cells and the culture medium were significantly higher in 3T3$\mathrm{L} 1$ adipocytes compared to those in preadipocytes $(p<0.05)$. The oil droplets are increased in differentiated adipocytes (Koopman et al., 2001), and thus OROSM is one of the most important indicators of the adipocyte differentiation. Figure $1 \mathrm{~b}$ showed adipocytes treated with MG significantly increased the accumulation of oil droplets compared with the MG-untreated group $(p<0.05)$.

\subsection{Expressions of $p-J N K, p-p 65, I L-6$, and MCP-1 in MG-in- duced insulin resistance}

Insulin resistance is caused by obesity through JNK pathway 
(Kaminska, 2005; Lee and Lee, 2014). In addition, JNK activation promotes the production of cytokines, such as IL-6, TNF- $\alpha$, and IL-1 $\beta$ (Kaminska, 2005; Lee and Lee, 2014). As shown in Figure 2a, p-JNK expression was significantly increased after $48 \mathrm{~h}$ of $\mathrm{MG}$ induction $(p<0.05)$. Therefore, MG may promote the inflammatory response through JNK pathway. NF- $\mathrm{KB}$ consists of two subunits, $\mathrm{p} 50$ and $\mathrm{p} 65$. When NF- $\mathrm{KB}$ is activated, p-p65 translocates into the nucleus and activates the target gene transcription (Kopitar-Jerala, 2015). As shown in Figure 2b, the expression of p-p65 was significantly increased after $48 \mathrm{~h}$ of $\mathrm{MG}$ induction $(p<0.05)$. IL-6 protein is one of major pro-inflammatory cytokines secreted by adipocytes in insulin-resistant human (Rotter et al., 2003). These results showed that IL-6 protein expression and release were significantly increased after $48 \mathrm{~h}$ of MG induction $(p<0.05)$ (Figure $2 \mathrm{c}, \mathrm{d})$. Therefore, MG increased pro-inflammatory cytokines. Obese patients are often accompanied by chronic inflammation, which leads to the development of many chronic diseases such as insulin resistance, fatty liver, and high blood pressure (Ye, 2013). In addition, MCP-1 could induce macrophage infiltration (Deshmane et al., 2009; Panee, 2012). Figure 2e showed that MCP-1 was markedly increased after $48 \mathrm{~h}$ of MG induction $(p<0.05)$. Therefore, MG can increase the expression of MCP-1 expression, thereby enhancing the possibility of macrophage infiltration to generate inflammation.

\subsection{Effect of MG on glucose uptake, PPARY, and C/EBPQ in 3T3- L1 adipocytes}

MG reduces glucose uptake and causes insulin resistance through reduction of insulin signaling pathway (Jia and $\mathrm{Wu}, 2007$ ). Figure 3a shows that glucose intake was significantly reduced after $48 \mathrm{~h}$ of MG induction $(p<0.05)$. Thus, MG decreased glucose uptake in adipocytes, which may cause insulin resistance. As shown in Figure 1b, MG enhances the oil droplet generation of 3T3-L1 adipocytes which may be regulated by PPAR $\gamma$ and $\mathrm{C} / \mathrm{EBP} \alpha$. PPAR $\gamma$ is activated by $\mathrm{C} / \mathrm{EBP} \beta$ and $\mathrm{C} / \mathrm{EBP} \delta$, and then activates $\mathrm{C} / \mathrm{EBP} \alpha$. PPAR $\gamma$ and $\mathrm{C} / \mathrm{EBP} \alpha$ can furtherly activate ACC and FAS. ACC and FAS accelerate the synthesis of triacylglycerol and accumulate the oil droplets. Figure $3 \mathrm{~b}$ and c shows that MG significantly increased the protein expressions of PPAR $\gamma$ and C/EBP $\alpha$ in adipocytes compared to the MG-untreated group $(p<0.05)$. Therefore, MG can promote the accumulation of oil droplets through upregulation of PPAR $\gamma$ and $\mathrm{C} / \mathrm{EBP} \alpha$ proteins.

\subsection{Effect of WEPE on glucose uptake and the protein expres- sions of IL-6, $p$-JNK, p-p65, and MCP-1 in MG-induced insulin resistance}

MG is a highly reactive metabolite of carbohydrates. When MG and MG-derivatives AGEs are increased, it may force development of insulin resistance (Vidal et al., 2014). MG levels are also higher in diabetic patient (Zhu et al., 2015). Aminoguanidine (AG), an investigational drug, acts to reduce the level of advanced glycation end products (AGEs) through interacting with 3-deoxyglucosone (Matsui et al., 2017). In here, we intended to compare the therapeutic effects between AG and WEPE on MG-induced insulin resistance. As shown in Figure 4a, WEPE effectively improved the glucose uptake of MG-induced adipocytes $(p<0.05)$. Obesity can be divided into adipocyte hyperplasia and hypertrophy. Adipocyte hyperplasia occurs in early childhood and pregnancy, and adipocyte hypertrophy occurs mainly in the adults. Adipocyte hypertrophy is usually accompanied with IL- 6 and TNF- $\alpha$, which induces insulin resistance (Abranches et al., 2015). Figure 4b and c show pro-inflammatory cytokine IL-6 protein expression and release were both significantly decreased in MG-adipocytes treated with WEPE $(p<0.05)$. Figure $4 d$ indicates that $\mathrm{p}$-p65 protein expression was significantly reduced by treatment with WEPE after $48 \mathrm{~h}$ of MG induction of 3T3-L1 adipocytes $(p<0.05)$. Thus, WEPE could significantly inhibit IL-6 and p-p65 protein expression induced by MG and thus reduce inflammation. MCP-1 is one of the inflammatory markers, mainly in adipose tissue, which can induce macrophage infiltration. Serum MCP-1 levels are higher in obese patients and patients with insulin resistance (Kamei et al., 2006). As shown in Figure 4e, WEPE significantly reduced MCP-1 protein expression $(p<0.05)$ induced by MG, and therefore WEPE can alleviate the MG-induced macrophage infiltration. When cells are stimulated by oxidative stress or proinflammatory cytokines, the MAPK signaling cascade is activated by ERK, JNK, and p38 (Johnson and Lapadat, 2002) that is involved in cell growth, differentiation, inflammation, and apoptosis (Singh et al., 2014). Figure $4 \mathrm{f}$ shows that $\mathrm{p}-\mathrm{JNK}$ protein expression was significantly increased after treatment of MG in adipocytes $(p<0.05)$. However, WEPE effectively attenuated p-JNK $(p<0.05)$. Therefore, WEPE improves inflammation by down-regulating the expression of MAPK-related proteins.

\subsection{Effect of WEPE on the protein expressions of PTP1B, PPARY, $C / E B P \alpha, p-A C C$, and FAS in MG-induced insulin resistance}

MG causes ROS and oxidative stress, in which endoplasmic reticulum stress plays an important regulatory function. Protein tyrosine phosphatase 1B (PTP1B) belongs to the family of protein tyrosine phosphatase (PTP). Endoplasmic reticulum stress reduces the activity of the tyrosine kinase on the insulin receptor, leading to the blockage of insulin pathway to cause insulin resistance (Cheng et al., 2012). Figure 5a indicates that MG-induced adipocytes show PTP1B protein expression decreasings significantly after treatment with WEPE $(p<0.05)$. PPAR $\gamma$ and $\mathrm{C} / \mathrm{EBP} \alpha$ are the major indicators of differentiated adipocytes (Kim et al., 2012; Ilavenil et al., 2014). As shown in Figure 5b, WEPE significantly decreased the protein expressions of PPAR $\gamma$ and C/EBP $\alpha$ induced by MG ( $p$ $<0.05)$. Acetyl-CoA carboxylase (ACC) and fatty acid synthase (FAS) are the key proteins in the development of obesity (Tan et al., 2011). ACC is the first step of the enzyme for the synthesis of fatty acids. Thus, the inhibition of p-ACC can reduce triacylglycerol synthesis, and then decrease fat accumulation. Figure $5 \mathrm{c}$ shows that WEPE significantly reduced the expression of p-ACC in the adipocytes after $48 \mathrm{~h}$ of MG induction $(p<0.05)$, and thus WEPE can alleviate the activation of ACC to reduce lipid accumulation. The FAS is an important enzyme in lipid synthesis. Figure $5 \mathrm{c}$ showed that WEPE significantly reduced the protein expression of FAS $(p<0.05)$. Therefore, WEPE can regulate fat synthesis related proteins induced by MG, and thus may decrease the deposition of oil droplets in adipose.

\subsection{Effect of ellagic acid on glucose uptake and IL-6 level in MG-induced insulin resistance}

P. emblica is a rich source of various phytochemicals such as ellagic acid, gallic acid, kaempferol, and quercetin, all of which are excellent for capturing free radical and controlling lipid damage and DNA oxidation (Singh et al., 2015). Among them, the main constituents of WEPE are ellagic acid ( $4.8 \mathrm{mg} / \mathrm{g}$ of crude extract) and gallic acid $(1.8 \mathrm{mg} / \mathrm{g}$ of crude extract). As shown in Figure 

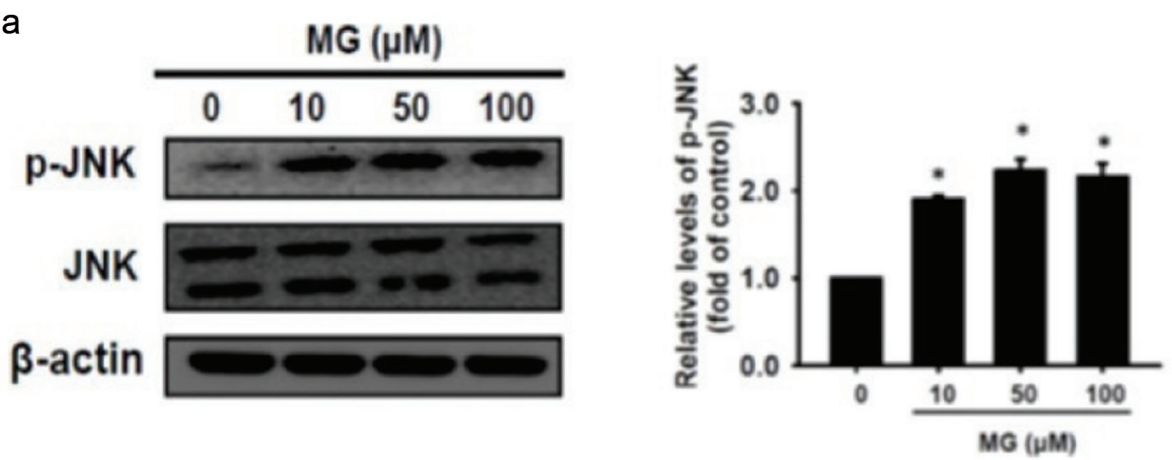

b
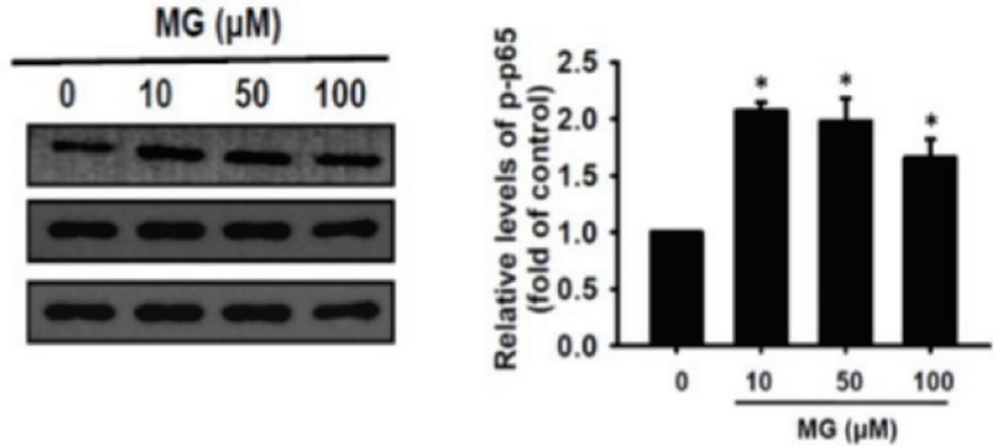

C

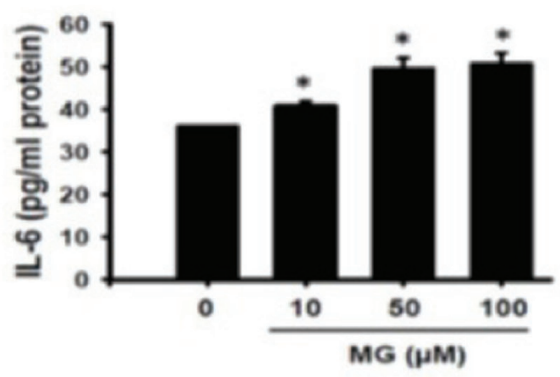

d
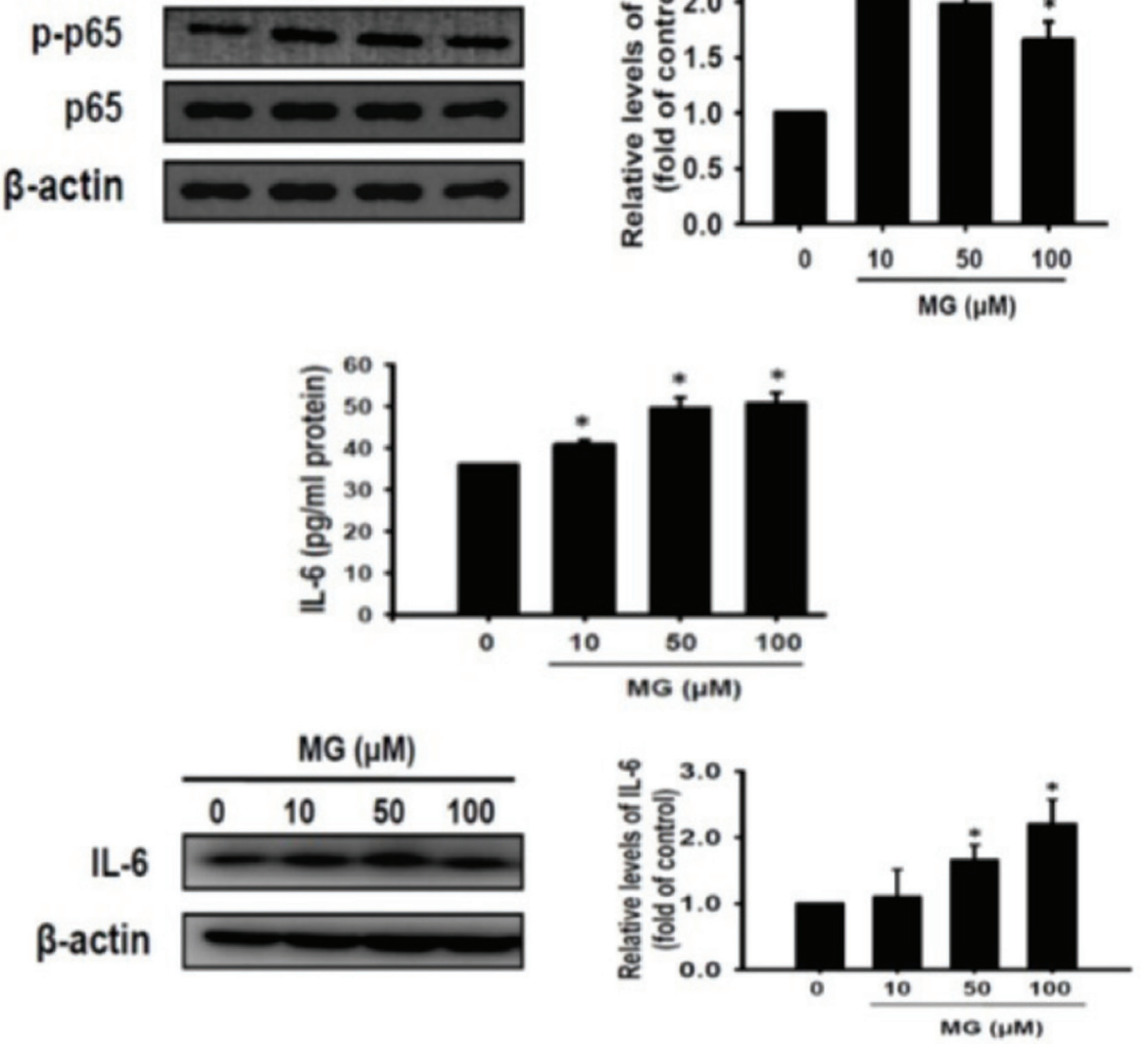

e
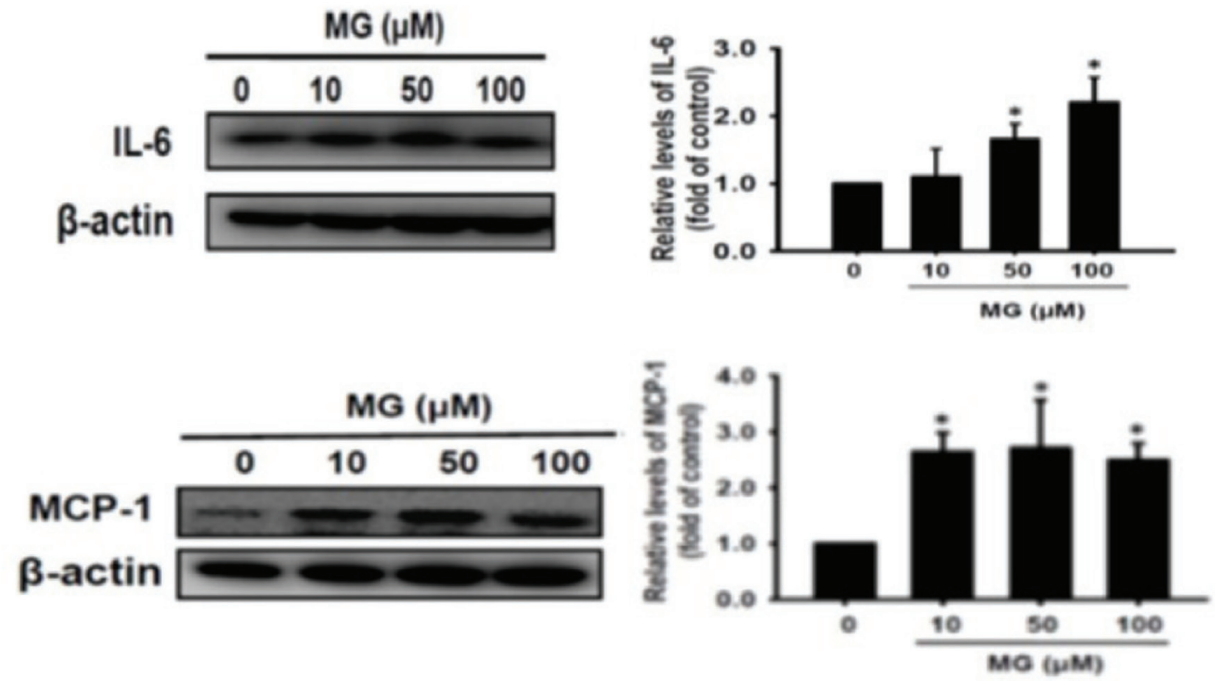

Figure 2. Inflammatory relative cytokine and chemokine production promoted by MG initiated signaling. 3T3-L1 adipocytes were treated with 10, 50, and $100 \mu \mathrm{M}$ of MG for $48 \mathrm{~h}$, respectively. (a) p-JNK protein, (b) p-p65 protein, (c) IL-6 release, (d) IL-6 protein, and (e) MCP-1 protein expression were measured using western blot and ELISA assay. The data were expressed as the mean $\pm \mathrm{SD}(n=3){ }^{*} p<0.05$ compared to untreated control. 


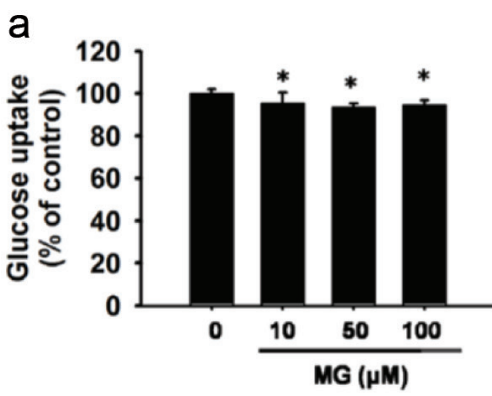

b

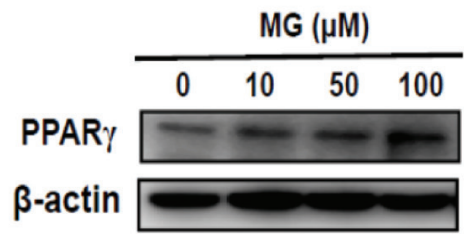

C

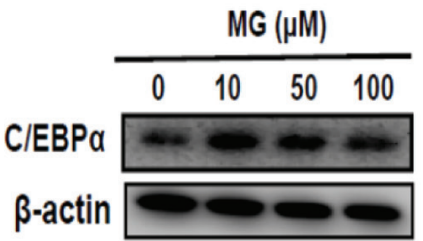

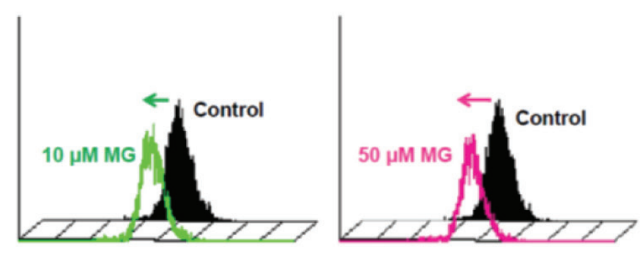
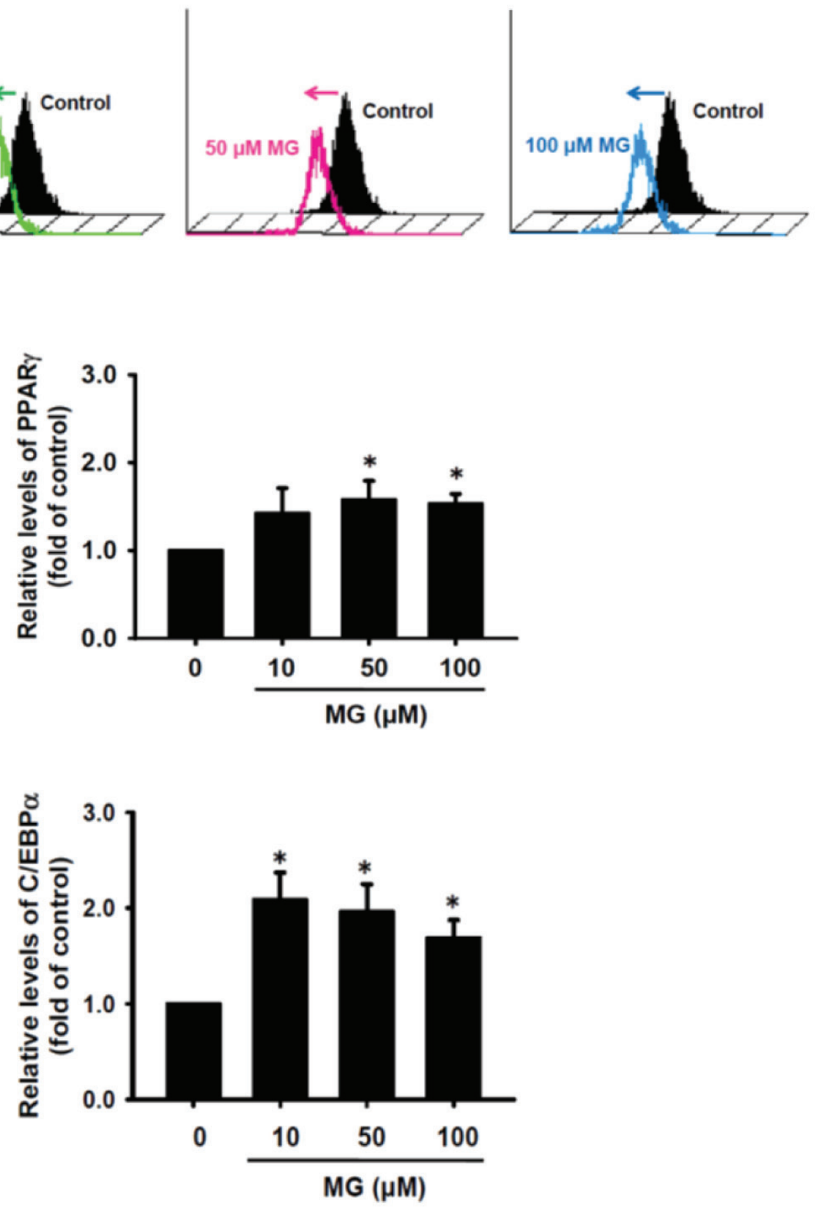

Figure 3. MG not only reduced glucose uptake also enhanced oil droplets accumulation-associated PPAR $\mathbf{a n d} C / \mathrm{EBP} \alpha$ proteins expression. (a) Cells were treated with MG for $24 \mathrm{~h}$. The glucose uptake assay was performed using flow cytometry. After MG treatment for $48 \mathrm{~h}$, protein expressions of (b) PPAR $\mathrm{p}$ and (c) C/EBP $\alpha$ were assessed by western blot. The data were expressed as the mean \pm SD $(n=3)$. ${ }^{*} p<0.05$ compared to untreated control.

6a, IL-6 was elevated by treatment of MG with adipocytes for 48 h. However, ellagic acid alone or co-treatment with ellagic acid and gallic acid both showed a significant reduction in MG-induced IL-6 secretion $(p<0.05)$, and their inhibitory activities were similar to that of AG. On the other hand, ellagic acid could improve the release of IL-6 in a dose-dependent manner $(p<0.05)$ (Figure $6 b)$. In addition, ellagic acid may also effectively improve the glucose uptake of MG-induced insulin resistance $(p<0.05)$ (Figure $6 c$ ).

\section{Discussion}

Metabolic syndrome patients generally have a higher amount of MG (Vidal et al., 2014). MG enhances free radicals, thus resulting in oxidative stress and inflammation (Matafome et al., 2013). The use of botanical plants is gaining renewed interest in the treatment of some clinical disorders. In the present study, MG was used to induce adipocytes, which establishes the cell model of inflammation and insulin resistance. The results so obtained showed that WEPE effectively improved MG-induced IL-6 secretion in adipocytes (Figure 4b, c). Dang et al. (2011) showed that WEPE has a good anti-inflammatory effect in acetic acid-induced peritonitis in mice. Muthuraman et al. (2011) showed that phenolic compounds of $P$. emblica can reduce acute inflammation induced by carrageenan in rats. P. emblica has a high content of ellagic acid and gallic acid (D'Souza et al., 2014). Therefore, we investigated whether treatment withellagic acid and gallic acid would improve pro-inflammatory effect. These results showed that ellagic acid significantly reduced IL-6 protein expression and cytokine release in MG-induced adipocytes, whereas gallic acid did not (Figure 6a, b). Therefore, ellagic acid plays a pivotal role in anti-inflammatory effect belongs to WEPE. Seo et al. (2016) showed that ellagic acid can inhibit the production of $\mathrm{PGE}_{2}$, TNF- $\alpha$, and IL-6 induced by LPS. Therefore, ellagic acid can effectively reduce IL-6 to alleviate inflammation.

External stimulus causes inflammation through MAPK pathway (Kaminska, 2005). Yamawaki et al. (2008) pointed out that acute induction of MG activates p-JNK to cause inflammation. Barnes and Karin (1997) showed that NF- $\mathrm{KB}$ activation may be mediated by phosphorylation of $I \kappa B \alpha$, which is positively associated with chronic inflammation. As shown in Figure $2 \mathrm{a}$ and $\mathrm{b}$, MG induced inflammation through the activation of JNK and p65 pathway. However, WEPE can decrease p-p65 protein (Figure 4d) 

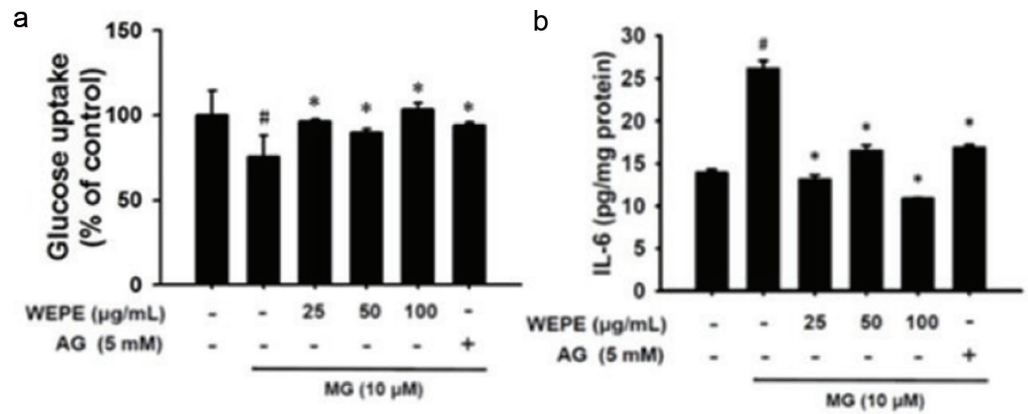

C

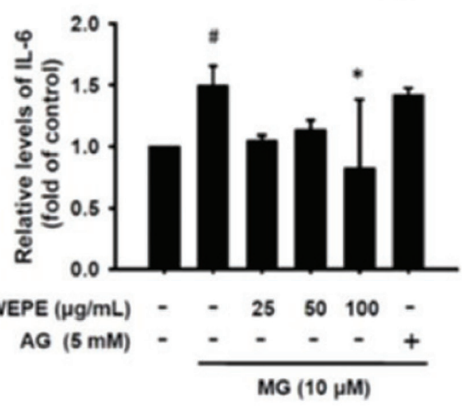

d

IL-6

B-actin

WEPE $(\mu \mathrm{g} / \mathrm{mL})$ - $\quad 2550100 \quad-$

$A G(5 \mathrm{mM})=-\quad-\quad-\quad+$

$M G(10 \mu M)$

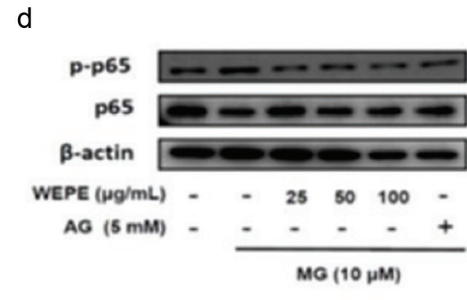

e

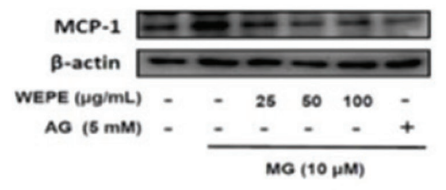

f

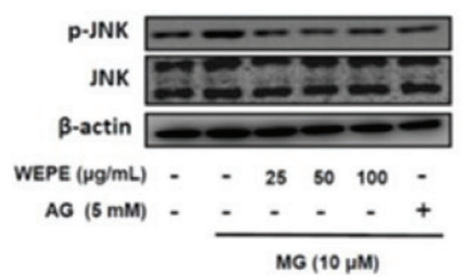

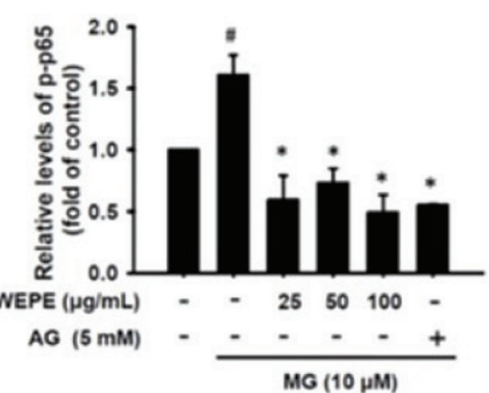
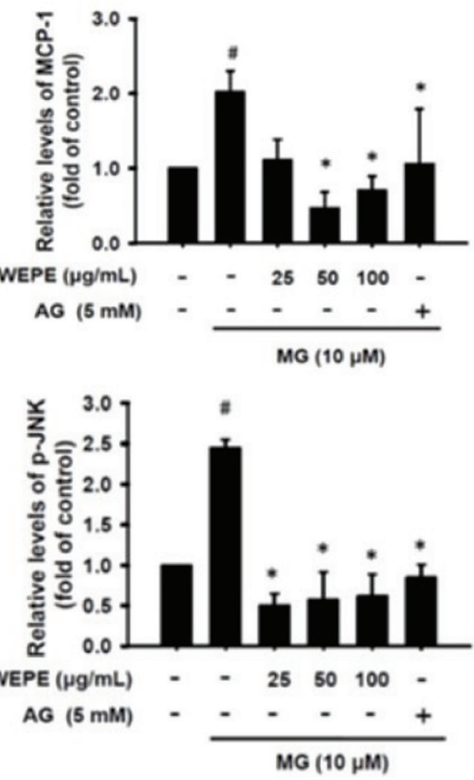

Figure 4. WEPE effectively inhibited glucose uptake and attenuated inflammatory relative signaling initiated by MG treatment. (a) MG treatment combined with or without WEPE and $5 \mathrm{mM}$ AG treatment in 3T3-L1 adipocytes for $24 \mathrm{~h}$. The glucose uptake assay was performed using flow cytometry. (b) IL-6 secretion and (C-F) protein expressions of IL-6, p-p65, MCP-1, and p-JNK in MG-treated 3T3-L1 adipocytes combined with or without WEPE and 5 mM AG treatment for $48 \mathrm{~h}$. The data were expressed as the mean $\pm \mathrm{SD}(n=3) .{ }^{\#} p<0.05$ compared to untreated control; * $p<0.05$ compared to MG-induced adipocytes. 
a
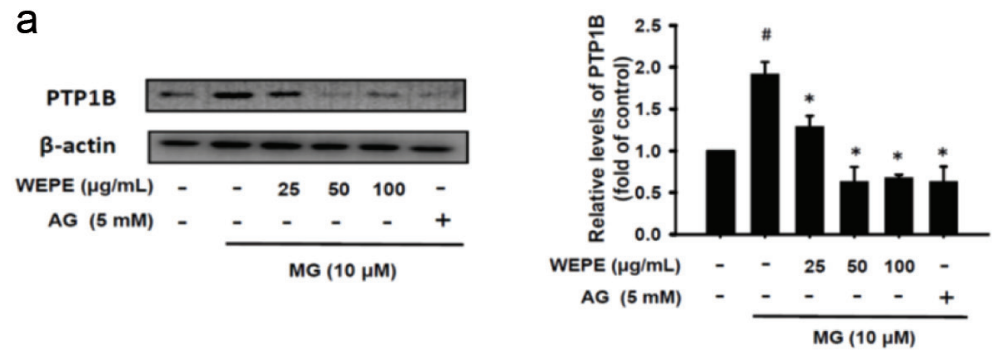

b
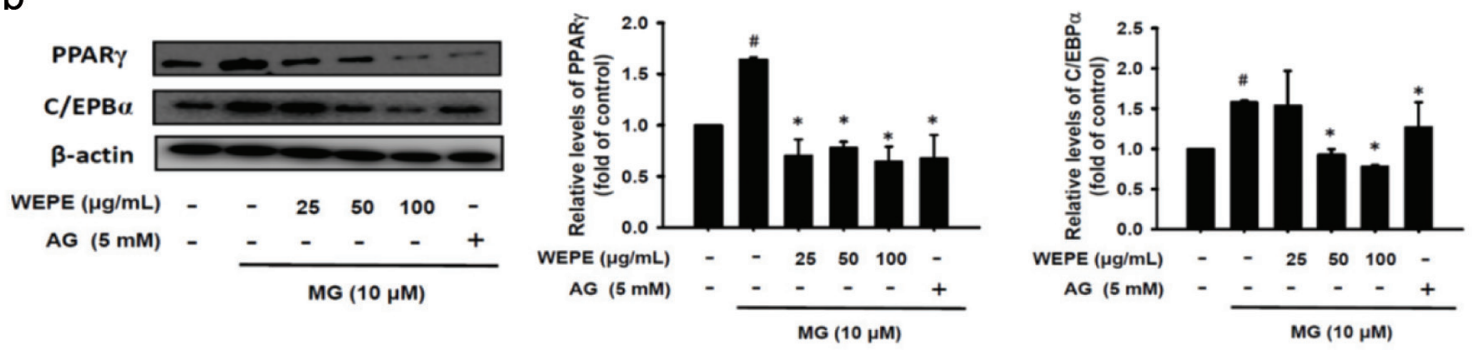

C
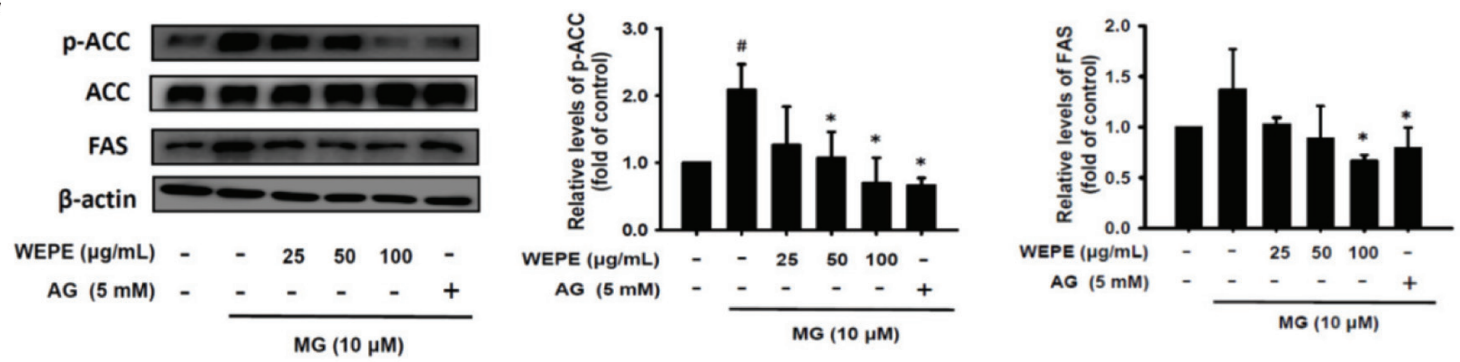

Figure 5. WEPE decreased fat synthesis related proteins expression induced by MG treatment. MG-treated 3T3-L1 adipocytes combined with or without WEPE and $5 \mathrm{mM}$ AG treatment for $48 \mathrm{~h}$. Protein expressions of (a) PTP1B, (b) PPAR $\gamma$ and C/EBP $\alpha$, and (c) p-ACC and FAS were measured by western blot, respectively. The data were expressed as the mean \pm SD $(n=3) .{ }^{*} p<0.05$ compared to untreated control; ${ }^{*} p<0.05$ compared to MG-induced adipocytes.

and p-JNK (Figure 4f) after $48 \mathrm{~h}$ of MG induction.

MCP-1 plays an important role in the migration of macrophages, which promotes the infiltration of macrophages in the adipose tissue resulting in chronic inflammation. As shown in Figure 2e, MG increased MCP-1 protein expression in adipocytes, indicating that MG promoted macrophage infiltration to result in inflammation. In addition, WEPE significantly decreased MCP-1 protein expression (Figure 4e). When inflammation is increased, adipocytes can easily lead to insulin resistance (de Luca and Olefsky, 2008). Figure 3 a shows that MG significantly reduced glucose uptake to cause insulin resistance. Jia and Wu (2007) also demonstrated that MG may reduce glucose uptake and lead to insulin resistance through reducing the activation of insulin pathway such as IR, IRS-1 and PI3K. However, WEPE and its major compound, ellagic acid, could increase the glucose uptake ability in adipocytes (Figures 4a, 6c). Kalekar et al. (2013) showed that $200 \mu \mathrm{g} /$ $\mathrm{mL}$ of $P$. emblica could increase the glucose uptake of adipocytes. Akhtar et al. (2011) showed that diabetic patients receiving 1, 2 or $3 \mathrm{~g}$ of Emblica officinalis powder per day for 21 days significantly decreased the fasting and 2-h post-prandial blood glucose levels. Therefore, WEPE can improve obesity-induced insulin resistance and the risk of developing type 2 diabetes, in which ellagic acid may play an important role.

PTP1B is one of the targets for the development of new drugs for diabetes (Teng et al., 2011). Cheng et al. (2012) showed that $\mathrm{MG}$ results in an increase in PTP1B expression; however, resvera- trol may attenuate PTP1B protein expression. The results of this study also showed that the expression of PTP1B was increased after MG-induced adipocytes (Figure 5a); however, WEPE could significantly reduce PTP1B protein. $\mathrm{PPAR} \gamma$ and $\mathrm{C} / \mathrm{EBP} \alpha$ play an important role in the differentiation of adipocytes (Song et al., 2013). In this study, we found that MG could significantly promote the expressions of PPAR $\gamma$ and $\mathrm{C} / \mathrm{EBP} \alpha$ in adipocytes (Figure 3b, c); however, WEPE significantly inhibited the protein expressions of PPAR $\gamma$ and $\mathrm{C} / \mathrm{EBP} \alpha$ (Figure $5 \mathrm{~b}$ ). Obesity is caused by imbalances in energy intake and energy expenditure, and excessive energy tends to form triacylglycerols that accumulate in cells to make cell hypertrophy (Fruhbeck et al., 2001). PPAR $\gamma$ and C/EBP $\alpha$ can activate ACC and FAS to increase the efficiency of lipid synthesis (Oh et al., 2016). The results showed that WEPE can reduce the protein expressions of PPAR $\gamma$ and $\mathrm{C} / \mathrm{EBP} \alpha$ (Figure $5 \mathrm{~b}$ ), and thus inhibit the p-ACC and FAS proteins (Figure $5 \mathrm{c}$ ) to reduce fat accumulation in adipocytes. Berndt et al. (2007) suggested that FAS is associated with lipid accumulation, which leads to a decrease in insulin sensitivity and an increase in fasting serum insulin, IL-6, leptin and the retinol-retinol- binding protein (RBP4). Therefore, the lipid synthesis pathway plays an important role in the disorders of energy metabolism, obesity and type 2 diabetes. Previous studies have shown that ellagic acid can reduce triacylglycerol and fat accumulation by reducing PPAR $\gamma$ and C/EBP $\alpha$ (Wang et al., 2013; Woo et al., 2015). Akhtar et al. (2011) showed that $P$. emblica can also reduce triacylglycerols in normal human beings and diabetic 
a

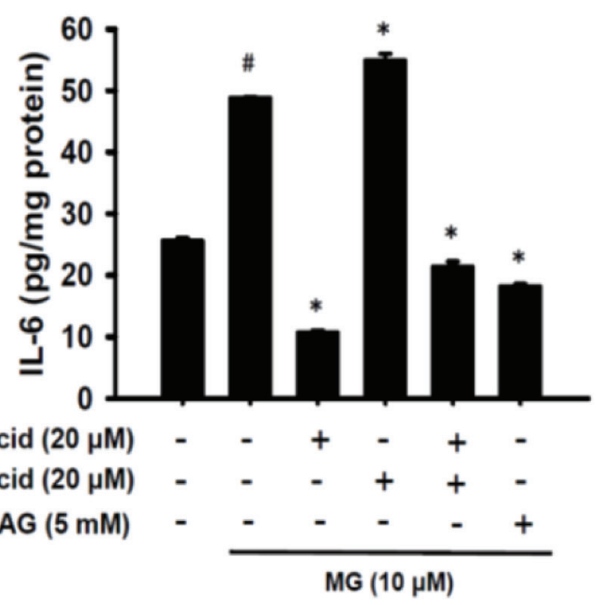

b

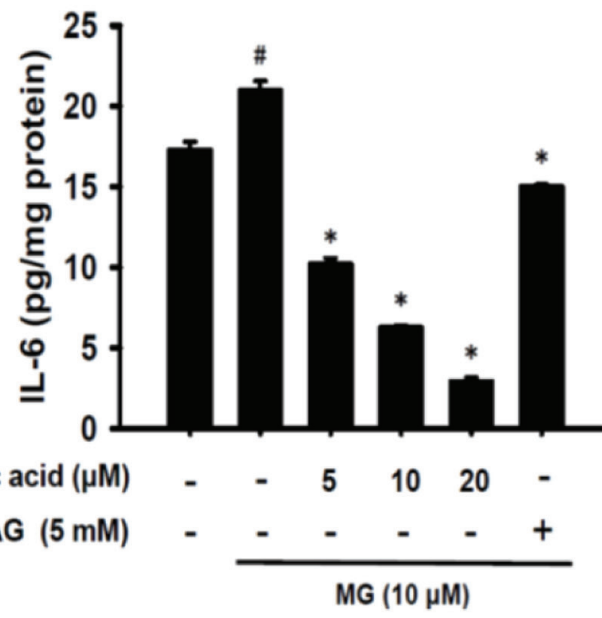

C

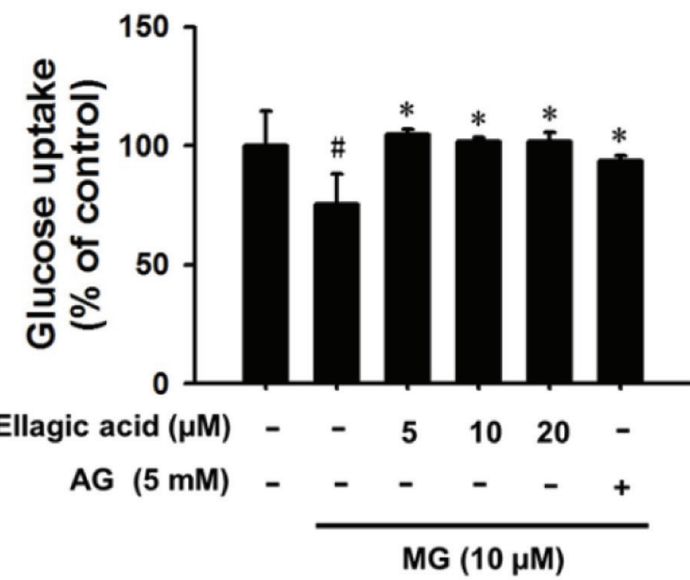

Figure 6. Ellagic acid dramatically inhibited IL-6 secretion and raised glucose uptake in MG-induced insulin resistance. (a) MG-treated 3T3-L1 adipocytes combined with or without $20 \mu \mathrm{M}$ ellagic acid and $20 \mu \mathrm{M}$ gallic acid treatment for $48 \mathrm{~h}$. IL-6 production was accessed using ELIAS assay. (b) MG-treated 3T3-L1 adipocytes combined with or without ellagic acid (5, 10 , and $20 \mu \mathrm{M}$ ) treatment for $48 \mathrm{~h}$. IL-6 production was measured by ELIAS assay. (c) Cell treatment condition of glucose uptake was the same as in (b) but treatment for $24 \mathrm{~h}$. Glucose uptake was measured by flow cytometry. The data were expressed as the mean \pm SD $(n=3)$. ${ }^{\#} p<0.05$ compared to untreated control; * $p<0.05$ compared to MG-induced adipocytes. patients. Therefore, WEPE may offer a potential opportunity for the development of new dietary supplement for inflammation, obesity, and type 2 diabetes.

\section{Conclusion}

MG enhances the expression and release of IL- 6 by activating JNK and p65 in inflammatory pathways, and increases PPAR $\gamma$ and C/ $\mathrm{EBP} \alpha$ in MG-induced insulin resistance. In addition, MG also promotes MCP-1 protein and decreases glucose uptake, which leads to the occurrence of insulin resistance and chronic diseases. P. emblica fruit has various bioactivities, such as anti-inflammatory, lipidlowering, anti-cancer, antioxidant, and treatment of diabetes. In this study, the results showed that WEPE improved inflammation, glucose uptake, and lipid accumulation, thereby it might play an important role in regulating obesity, inflammation, and insulin resistance. In the further, . emblica fruit has the potential to develop healthy food for regulating blood lipids and blood sugar.

\section{Conflict of interest}

The authors declare no conflict of interest.

\section{References}

Abranches, M.V., Oliveira, F.C., Conceicao, L.L., and Peluzio, M.D. (2015) Obesity and diabetes: the link between adipose tissue dysfunction and glucose homeostasis. Nutr. Res. Rev. 28: 121-132.

Akhtar, M.S., Ramzan, A., Ali, A., and Ahmad, M. (2011). Effect of Amla fruit (Emblica officinalis Gaertn.) on blood glucose and lipid profile of normal subjects and type 2 diabetic patients. Int. J. Food Sci. Nutr. 62: 609-616.

Ansari, A., Shahriar, M.S., Hassan, M.M., Das, S.R., Rokeya, B., Haque, M.A., Haque, M.E., Biswas, N., and Sarkar, T. (2014). Emblica officinalis improves glycemic status and oxidative stress in STZ induced type 2 diabetic model rats. Asian Pac. J. Trop. Med. 7: 21-25.

Arribas-Lorenzo, G., and Morales, F.J. (2010). Analysis, distribution, and dietary exposure of glyoxal and methylglyoxal in cookies and their relationship with other heat-induced contaminants. J. Agric. Food Chem. 58: 2966-2972.

Barnes, P.J., and Karin, M. (1997). Nuclear factor-kappaB: a pivotal transcription factor in chronic inflammatory diseases. N. Engl. J. Med. 336: 1066-1071.

Berndt, J., Kovacs, P., Ruschke, K., Kloting, N., Fasshauer, M., Schon, M.R., Korner, A., Stumvoll, M., and Bluher, M. (2007). Fatty acid synthase gene expression in human adipose tissue: association with obesity and type 2 diabetes. Diabetologia. 50: 1472-1480.

Bo, J., Xie, S., Guo, Y., Zhang, C., Guan, Y., Li, C., Lu, J., and Meng, Q.H. (2016). Methylglyoxal Impairs Insulin Secretion of Pancreatic betaCells through Increased Production of ROS and Mitochondrial Dysfunction Mediated by Upregulation of UCP2 and MAPKs. J. Diabetes Res. 2016: 2029854.

Brix, J.M., Hollerl, F., Kopp, H.P., Schernthaner, G.H., and Schernthaner, G. (2012). The soluble form of the receptor of advanced glycation endproducts increases after bariatric surgery in morbid obesity. Int. J. Obes. (Lond). 36: 1412-1417.

Cheng, A.S., Cheng, Y.H., Chiou, C.H., and Chang, T.L. (2012). Resveratrol upregulates Nrf2 expression to attenuate methylglyoxal-induced insulin resistance in Hep G2 cells. J. Agric. Food Chem. 60: 9180-9187.

Cheng, Y.T., Ho, C.Y., Jhang, J., Lu, C.C., and Yen, G.C. (2014). DJ-1 plays an important role in caffeic acid-mediated protection of the gastrointestinal mucosa against ketoprofen-induced oxidative damage. J. Nutr. Biochem. 25: 1045-1057

Dang, G.K., Parekar, R.R., Kamat, S.K., Scindia, A.M., and Rege, N.N. (2011). 
Antiinflammatory activity of Phyllanthus emblica, Plumbago zeylanica and Cyperus rotundus in acute models of inflammation. Phytother. Res. 25: 904-908.

De Luca, C., and Olefsky, J.M. (2008). Inflammation and insulin resistance. FEBS Lett. 582: 97-105.

Deshmane, S.L., Kremlev, S., Amini, S., and Sawaya, B.E. (2009). Monocyte chemoattractant protein-1 (MCP-1): an overview. J. Interferon Cytokine Res. 2: 313-326.

Dong, K., Ni, H., Wu, M., Tang, Z., Halim, M., and Shi, D. (2016). ROS-mediated glucose metabolic reprogram induces insulin resistance in type 2 diabetes. Biochem. Biophys. Res. Commun. 476(4): 204-211.

D'Souza, J.J., D'Souza, P.P., Fazal, F., Kumar, A., Bhat, H.P., and Baliga, M.S. (2014). Anti-diabetic effects of the Indian indigenous fruit Emblica officinalis Gaertn: active constituents and modes of action. Food Funct. 5: 635-644.

Fruhbeck, G., Gomez-Ambrosi, J., Muruzabal, F.J., and Burrell, M.A. (2001). The adipocyte: a model for integration of endocrine and metabolic signaling in energy metabolism regulation. Am. J. Physiol. Endocrinol. Metab. 280: E827-847.

Fugh-Berman, A. (2000). Herbs and dietary supplements in the prevention and treatment of cardiovascular disease. Prev. Cardiol. 3: 24-32.

Gerriets, V.A., and Maclver, N.J. (2014). Role of T cells in malnutrition and obesity. Front Immunol. 5: 379.

Hammond, R.A., and Levine, R. (2010). The economic impact of obesity in the United States. Diabetes Metab. Syndr. Obes. 3: 285-295.

Han, T.S., and Lean, M.E. (2016). A clinical perspective of obesity, metabolic syndrome and cardiovascular disease. JRSM Cardiovasc. Dis. 5: 2048004016633371.

Ilavenil, S., Arasu, M.V., Lee, J.C., Kim da, H., Vijayakumar, M., Lee, K.D., and Choi, K.C. (2014). Positive regulations of adipogenesis by Italian ryegrass [Lolium multiflorum] in 3T3-L1 cells. BMC Biotechnol. 14: 54.

Jia, X., and Wu, L. (2007). Accumulation of endogenous methylglyoxal impaired insulin signaling in adipose tissue of fructose-fed rats. Mol. Cell Biochem. 306: 133-139.

Johnson, G.L., and Lapadat, R. (2002). Mitogen-activated protein kinase pathways mediated by ERK, JNK, and p38 protein kinases. Science. 298: 1911-1912.

Kalekar, S.A., Munshi, R.P., Bhalerao, S.S., and Thatte, U.M. (2013). Insulin sensitizing effect of 3 Indian medicinal plants: an in vitro study. Indian J. Pharmacol. 45: 30-33.

Kamei, N., Tobe, K., Suzuki, R., Ohsugi, M., Watanabe, T., Kubota, N., Ohtsuka-Kowatari, N., Kumagai, K., Sakamoto, K., Kobayashi, M., Yamauchi, T., Ueki, K., Oishi, Y., Nishimura, S., Manabe, I., Hashimoto, H., Ohnishi, Y., Ogata, H., Tokuyama, K., Tsunoda, M., Ide, T., Murakami, K., Nagai, R., and Kadowaki, T. (2006). Overexpression of monocyte chemoattractant protein-1 in adipose tissues causes macrophage recruitment and insulin resistance. J. Biol. Chem. 281: 26602-26614.

Kaminska, B. (2005). MAPK signalling pathways as molecular targets for anti-inflammatory therapy--from molecular mechanisms to therapeutic benefits. Biochim. Biophys. Acta. 1754: 253-262.

Kellow, N.J., Coughlan, M.T., Savige, G.S., and Reid, C.M. (2014). Effect of dietary prebiotic supplementation on advanced glycation, insulin resistance and inflammatory biomarkers in adults with pre-diabetes: a study protocol for a double-blind placebo-controlled randomised crossover clinical trial. BMC Endocr. Disord. 14: 55.

Kim, G.S., Park, H.J., Woo, J.H., Kim, M.K., Koh, P.O., Min, W., Ko, Y.G., Kim, C.H., Won, C.K., and Cho, J.H. (2012). Citrus aurantium flavonoids inhibit adipogenesis through the Akt signaling pathway in 3T3-L1 cells. BMC Complement Altern. Med. 12: 31.

Koopman, R., Schaart, G., and Hesselink, M.K. (2001). Optimisation of oil red $\mathrm{O}$ staining permits combination with immunofluorescence and automated quantification of lipids. Histochem Cell Biol. 116: 63-68.

Kopitar-Jerala, N. (2015). Innate Immune Response in Brain, NF-Kappa B Signaling and Cystatins. Front Mol. Neurosci. 8: 73.

Lee, B.C., and Lee, J. (2014). Cellular and molecular players in adipose tissue inflammation in the development of obesity-induced insulin resistance. Biochim. Biophys. Acta. 1842: 446-462.

Matafome, P., Sena, C., and Seica, R. (2013). Methylglyoxal, obesity, and diabetes. Endocrine. 43: 472-484.

Matsui, T., Higashimoto, Y., Nishino, Y., Nakamura, N., Fukami, K., and
Yamagishi SI, (2017). RAGE-Aptamer Blocks the Development and Progression of Experimental Diabetic Nephropathy. Diabetes. 66(6): 1683-1695.

Muthuraman, A., Sood, S., and Singla, S.K. (2011). The antiinflammatory potential of phenolic compounds from Emblica officinalis L. in rat. Inflammopharmacology. 19: 327-334.

Nain, P., Saini, V., Sharma, S., and Nain, J. (2012). Antidiabetic and antioxidant potential of Emblica officinalis Gaertn. Leaves extract in streptozotocin-induced type-2 diabetes mellitus (T2DM) rats. J Ethnopharmacol. 142: 65-71.

Oh, D.R., Kim, Y., Choi, E.J., Hunmi, L., Jung, M.A., Bae, D., Jo, A., Kim, Y.R., and Kim, S. (2016). Antiobesity Effects of Unripe Rubus coreanus Miquel and Its Constituents: An In Vitro and In Vivo Characterization of the Underlying Mechanism. Evid. Based Complement Alternat. Med. 2016: 4357656.

Panee, J. (2012). Monocyte Chemoattractant Protein 1 (MCP-1) in obesity and diabetes. Cytokine. 60: 1-12.

Qatanani, M., and Lazar, M.A. (2007). Mechanisms of obesity-associated insulin resistance: many choices on the menu. Genes Dev. 21: 14431455.

Rotter, V., Nagaev, I., and Smith, U. (2003). Interleukin-6 (IL-6) induces insulin resistance in 3T3-L1 adipocytes and is, like IL-8 and tumor necrosis factor-alpha, overexpressed in human fat cells from insulinresistant subjects. J. Biol. Chem. 278: 45777-45784.

Seo, C.S., Jeong, S.J., Yoo, S.R., Lee, N.R., and Shin, H.K. (2016). Quantitative Analysis and In vitro Anti-inflammatory Effects of Gallic Acid, Ellagic Acid, and Quercetin from Radix Sanguisorbae. Pharmacogn. Mag. 12: 104-108.

Sims, G.P., Rowe, D.C., Rietdijk, S.T., Herbst, R., and Coyle, A.J. (2010). HMGB1 and RAGE in inflammation and cancer. Annu. Rev. Immunol. 28: 367-388.

Singh, M.K., Yadav, S.S., Yadav, R.S., Chauhan, A., Katiyar, D., and Khattri, S. (2015). Protective effect of Emblica-officinalis in arsenic induced biochemical alteration and inflammation in mice. Springerplus. 4: 438.

Singh, V.P., Bali, A., Singh, N., and Jaggi, A.S. (2014). Advanced glycation end products and diabetic complications. Korean J. Physiol. Pharmacol. 18: 1-14.

Song, Y., Park, H.J., Kang, S.N., Jang, S.H., Lee, S.J., Ko, Y.G., Kim, G.S., and Cho, J.H. (2013). Blueberry peel extracts inhibit adipogenesis in 3T3-L1 cells and reduce high-fat diet-induced obesity. PLoS One. 8: e69925.

Tan, B., Yin, Y., Liu, Z., Tang, W., Xu, H., Kong, X., Li, X., Yao, K., Gu, W., Smith, S.B., and Wu, G. (2011). Dietary L-arginine supplementation differentially regulates expression of lipid-metabolic genes in porcine adipose tissue and skeletal muscle. J. Nutr. Biochem. 22: 441-445.

Teng, B.S., Wang, C.D., Yang, H.J., Wu, J.S., Zhang, D., Zheng, M., Fan, Z.H., Pan, D., and Zhou, P. (2011). A protein tyrosine phosphatase 1B ac tivity inhibitor from the fruiting bodies of Ganoderma lucidum (Fr.) Karst and its hypoglycemic potency on streptozotocin-induced type 2 diabetic mice. J. Agric. Food Chem. 59: 6492-6500.

Tikellis, C., Pickering, R.J., Tsorotes, D., Huet, O., Cooper, M.E., JandeleitDahm, K., and Thomas, M.C. (2014). Dicarbonyl stress in the absence of hyperglycemia increases endothelial inflammation and atherogenesis similar to that observed in diabetes. Diabetes. 63: 3915-3925.

Tung, Y.T., Huang, C.Z., Lin, J.H., and Yen, G.C. (2018). Effect of Phyllanthus emblica L. fruit on methionine and choline-deficiency diet-induced nonalcoholic steatohepatitis. J. Food Drug Anal. 26(4): 1245-1252.

Vidal, N., Cavaille, J.P., Graziani, F., Robin, M., Ouari, O., Pietri, S., and Stocker, P. (2014). High throughput assay for evaluation of reactive carbonyl scavenging capacity. Redox Biol. 2: 590-598.

Vlassara, H., and Striker, G.E. (2011). AGE restriction in diabetes mellitus: a paradigm shift. Nat. Rev. Endocrinol. 7: 526-539.

Wang, L., Li, L., Ran, X., Long, M., Zhang, M., Tao, Y., Luo, X., Wang, Y., Ma, X., Halmurati, U., Mao, X., and Ren, J. (2013). Ellagic Acid Reduces Adipogenesis through Inhibition of Differentiation-Prevention of the Induction of Rb Phosphorylation in 3T3-L1 Adipocytes. Evid. Based Complement Alternat. Med. 2013: 287534.

Woo, M.S., Choi, H.S., Seo, M.J., Jeon, H.J., and Lee, B.Y. (2015). Ellagic acid suppresses lipid accumulation by suppressing early adipogenic events and cell cycle arrest. Phytother. Res. 29: 398-406.

Yamawaki, H., Saito, K., Okada, M., and Hara, Y. (2008). Methylglyoxal me- 
diates vascular inflammation via JNK and p38 in human endothelial cells. Am. J. Physiol. Cell Physiol. 295: C1510-1517.

Ye, J. (2013). Mechanisms of insulin resistance in obesity. Front Med. 7 $14-24$.

Zhao, T., Sun, Q., Marques, M., and Witcher, M. (2015). Anticancer Prop- erties of Phyllanthus emblica (Indian Gooseberry). Oxid. Med. Cell Longev. 2015: 950890

Zhu, Y., Zhao, Y., Wang, P., Ahmedna, M., and Sang, S. (2015). Bioactive ginger constituents alleviate protein glycation by trapping methylglyoxal. Chem. Res. Toxicol. 28: 1842-1849. 